\title{
Development of instruments for seafloor geodesy
}

\author{
Hiromi Fujimoto $^{1}$, Kin-ichiro Koizumi ${ }^{1}$, Yukihito Osada ${ }^{1}$, and Toshihiko Kanazawa ${ }^{2}$ \\ ${ }^{1}$ Ocean Research Institute, University of Tokyo, 1-15-1 Minamidai, Nakano-ku, Tokyo 164-8639, Japan \\ ${ }^{2}$ Earthquake Research Institute, University of Tokyo, 1-1-1 Yayoi, Bunkyo-ku, Tokyo 113-0032, Japan
}

(Received April 2, 1998; Revised July 3, 1998; Accepted July 17, 1998)

\begin{abstract}
We have developed systems for measuring differential displacements across a fault zone, and examined their resolutions through seafloor experiments at relatively short baselines. A system for a seafloor extensometer makes use of precise acoustic ranging with a linear pulse compression technique. The system has a resolution better than $1 \mathrm{~cm}$ in acoustic ranging over a baseline of at least $1 \mathrm{~km}$. The most critical problem is correction for temperature variations, and we estimate that the effect can be corrected with $\mathrm{cm}$-order accuracy in the case of a deep-sea experiment. We have also examined a leveling system on the seafloor using an array of ocean bottom pressure gauges and an ocean bottom gravimeter to detect differential vertical motion. The system is estimated to have a resolution of several centimeters in vertical displacement. These system will be useful for triangulation and leveling on the seafloor, but we need further studies over a longer baseline and to achieve better long-term stability.
\end{abstract}

\section{Introduction}

Geodetic application of interferometric GPS observation has proved to be able to monitor not only the steady plate motions but also crustal deformations near plate boundaries. The tectonically most active areas are, however, usually difficult of direct access using GPS, because such areas are boundaries of oceanic plates under the deep water. Crustal deformations tend to be more time-variable as the location is nearer a plate boundary (e.g., Heki et al., 1993). We need systems for monitoring seafloor crustal movements to understand the physical mechanism of episodic events at the plate boundaries and motion of the lithosphere.

Precise underwater acoustic ranging has been pursued for precise seafloor geodesy using acoustic waves that can propagate more than ten kilometers in sea water (e.g., Spiess et al., 1994). Although acoustic ranging has severe limitations in resolution and in maximum range, a resolution of $1 \mathrm{~cm}$ at a baseline length of several kilometers is now a difficult but attainable target. An important problem of acoustic ranging is correction for variable sound velocity. We carried out a seafloor experiment to estimate the effect and the results are discussed below.

We are also developing systems for detecting differential displacements in vertical seafloor crustal movement by using ocean bottom pressure meters (OBPs) and an ocean bottom gravimeter (OBG). We plan to use an array of OBPs as a kind of leveling system. Revisiting observations of gravity and pressure can give some constraints on the effects of ocean dynamics and long-term drifts in seafloor leveling.

\section{Method of Measurements}

\subsection{Horizontal acoustic ranging}

Underwater positioning is usually carried out through

Copy right (C) The Society of Geomagnetism and Earth, Planetary and Space Sciences (SGEPSS); The Seismological Society of Japan; The Volcanological Society of Japan; The Geodetic Society of Japan; The Japanese Society for Planetary Sciences. ranging with acoustic waves of $10-20 \mathrm{kHz}$, and the resolution of ranging is about 1 meter. Since relative plate motions and the resultant crustal deformation near the plate boundaries are at most 10 centimeters per year, seafloor positioning or seafloor ranging should have a resolution of about $1 \mathrm{~cm}$. In order to achieve this resolution, linear pulse compression techniques developed for radar have been applied to acoustic ranging. Pulse compression allows an instrument to utilize a long pulse to achieve large radiated energy, but simultaneously to obtain the range resolution of a short pulse. It accomplishes this by employing phase or frequency modulation to widen the signal bandwidth. Spiess et al. (1994) have used phase-coded pulse compression (e.g., MacWilliams and Sloane, 1976), which is also used for the GPS. Yabuki et al. (1994) are developing a system using linear frequency modulated pulse compression with a chirp signal (Dicke, 1953), which is used for satellite altimetry.

We are developing a system using the phase modulation technique. In this form of pulse compression, a long pulse of duration $T$ is divided into $N$ subpulses each of width $\tau$. The phase of each subpulse is chosen to be either 0 or $\pi$ radians. If the subpulses are coded with pseudorandom noises, the output of the matched filter using cross-correlation function will be a spike of width $t$ with an amplitude $N$ times larger than that of the long pulse; the pulse-compression rate is $N=T / \tau$. A popular technique to make a pseudorandom noise code is the generation of a linear recursive sequence using a shift register with feedback. An $n$-stage ( $n$-bit) shift register can generate a binary sequence of period $2^{n}-1$, when it is called maximum length sequence, or m-sequence.

Precise acoustic ranging on the seafloor is a straightforward method to detect deformation across a fault zone at sea. Although the maximum range of a baseline is limited to be less than about $10 \mathrm{~km}$, this method has the advantage that it can be applied to any site in the open ocean irrespective of the distance from land. The method has another merit that tem- 
perature variations are fairly small in the deep sea; the most critical problem for acoustic ranging is the effect of variable temperature. We have developed and examined a ranging system using a 5 -stage $(N=31)$ or 7 -stage $(N=127) \mathrm{m}$ sequence acoustic signal. Because the carrier frequency of the acoustic signals is about $10 \mathrm{kHz}$, we can get the most probable two-way travel time with a resolution of about $0.1 \mathrm{~ms}$. In order to get finer resolution a signal is received with twofold cross correlation: one is with the reference signal and the other is with a modified reference signal with phase shift by 90 degrees. We can determine the phase of the carrier wave at the arrival of the signal from both of the results.

Problems for precise acoustic ranging in the oceans result from the nature of sound velocity which increases with temperature, salinity, and pressure (e.g., Mackenzie, 1981). The temperature effect on acoustic velocity is approximately $3 \times 10^{-6}$ for a temperature change of 1 millidegree. Fortunately temperatures are fairly stable in the deep sea and can be measured with a resolution of better than 0.1 millidegree. Therefore, the effect of temperature variations can be corrected, except for short-term fluctuations, with temperature data monitored along the baseline. Sound velocity varies by about $1 \times 10^{-5}$ with salinity variation of 0.01 per mill. Salinity is quite stable in the deep sea, and the effect on sound velocity is smaller than that of temperature. The pressure effect on sound velocity is about $5 \times 10^{-6}$ for ocean tide of $0.5 \mathrm{mH}_{2} \mathrm{O}$, and is easily corrected.

Pressure has another and serious effect on the horizontal acoustic ranging. Temperature and salinity is almost constant in the deep sea, and sound velocity increases with pressure. Because an acoustic wave bends to the region of lower velocity, it always bends upwards in the deep water. This is an important problem for experiments of horizontal seafloor acoustic ranging. There may be no problem, if acoustic units are installed on both sides of slopes facing a trough. If the seafloor is flat, however, it is necessary to hold the acoustic units to certain altitudes above the seafloor: for example, $1.9 \mathrm{~m}$ for ranging over $1.5 \mathrm{~km}$, and $22 \mathrm{~m}$ for the ranging over $5 \mathrm{~km}$. These are estimates for the seafloor of Sagami Bay, Central Japan, and the problem is more severe on the deep seafloor. Experiment over longer baselines becomes increasingly difficult.

\subsection{Detection of vertical movement}

Ocean bottom pressure measurements can contribute to monitoring vertical movements of the seafloor in two ways. An array of ocean bottom pressure gauges acts as monitoring system of relative vertical movements if the effects of shortwavelength ocean dynamics are weak. Atmospheric pressure variations are mostly compensated at the sea surface. Major events of ocean dynamics will be monitored from satellites. Simultaneous measurements of pressure and gravity can also be used to distinguish a pressure change due to seafloor deformation from that due to ocean dynamics. Suppose firstly the seafloor is uplifted by $1 \mathrm{~cm}$. The pressure value will decrease by $1 \mathrm{cmH}_{2} \mathrm{O}$. The gravity value will also decrease by $2.2 \mathrm{mi}-$ crogals $(-3.068$ microgals due to height change and +0.864 microgal due to reduced gravitational attraction of the global sea water). Suppose then the sea surface is lowered by $1 \mathrm{~cm}$. The pressure value will decrease by $1 \mathrm{cmH}_{2} \mathrm{O}$ in this case also, but the gravity value will increase by 0.432 microgals due to reduced gravitational attraction of the local sea water. The pressure value decreases in both cases, but the gravity shows a different response. If the measurements are carried out with a good $\mathrm{S} / \mathrm{N}$ ratio, simultaneous measurements can distinguish between the two effects.

We developed ocean bottom pressure meters (OBPs) with a quartz pressure gauge for each unit rated to $7000 \mathrm{~m}$ water depth (8B7000-2) manufactured by Paroscientific Inc. The sensor is equipped with a quartz thermometer for temperature correction. We also developed an ocean bottom gravimeter (OBG) for use by a submersible and for stand-alone measurements (Fujimoto et al., 1998). Free gimbals suspensions with an oil damper keep a sensor package of Scintrex CG-3M/SB roughly vertical and the effect of the remaining tilt is numerically corrected by the gravimeter. The gimbals and sensor are in a pressure-tight spherical housing made of titanium alloy rated to $7200 \mathrm{~m}$ water depth. The gravimeter system has recently been equipped with a self-surfacing mechanism and a battery unit. The system is designed for measurements of about two days. Although the gravity sensor is a special unit with lower operating temperature (about $36^{\circ} \mathrm{C}$ ), it still consumes considerable power on the seafloor at temperature near $0^{\circ} \mathrm{C}$.

\section{Results of Seafloor Experiments \\ 3.1 Horizontal acoustic ranging}

The effect of temperature variation on the acoustic ranging as well as the resolution of the ranging was examined in November 1995 through an experiment for one week on the shallow (about $1400 \mathrm{~m}$ deep) seafloor of Sagami Bay (Fujimoto et al., 1997). Two acoustic units with quartz thermometers were deployed on the bottom about $1500 \mathrm{~m}$ apart from each other as shown in Fig. 1. The seafloor was almost flat and the acoustic transducer of each unit was held $2.9 \mathrm{~m}$ above the seafloor. Two-way travel time of a 5-stage $\mathrm{m}$-sequence acoustic signal was measured by each unit every 10 minutes.

We estimated the resolution of ranging of the system by comparing the data measured simultaneously by the two instruments (unit A and B). The results showed that the measurements had ambiguities of $0.1 \mathrm{~ms}$, or about $7.5 \mathrm{~cm}$ in distance; it is because of an uncertainty in choosing the central peak in the cross correlation between signals. When one instrument measures two-way travel time along the route $\mathrm{A}-\mathrm{B}-\mathrm{A}$, the other successively makes another measurement along the route $\mathrm{B}-\mathrm{A}-\mathrm{B}$. We selected pairs of data measured by $A$ and $B$ which agree with each other within $0.1 \mathrm{~ms}$. Judging from the selected data, repeatability of the ranging was $1-2 \mathrm{~cm}$ except for the ambiguity indicating that phase of the carrier wave was correctly determined.

The effect of temperature was examined with the selected data and shown in Fig. 2. Observed values of two-way travel time of the acoustic signal (diamonds) were compared with those estimated from the temperature data (solid line) observed at the ends of the baseline. There were temperature variations of about $0.2^{\circ} \mathrm{C}$ induced by tidal bottom currents, and the effect was roughly corrected. The root mean square of the differences was $7 \mathrm{~cm}$ in distance (Fujimoto et al., 1997).

Because the residuals of temperature correction were much 


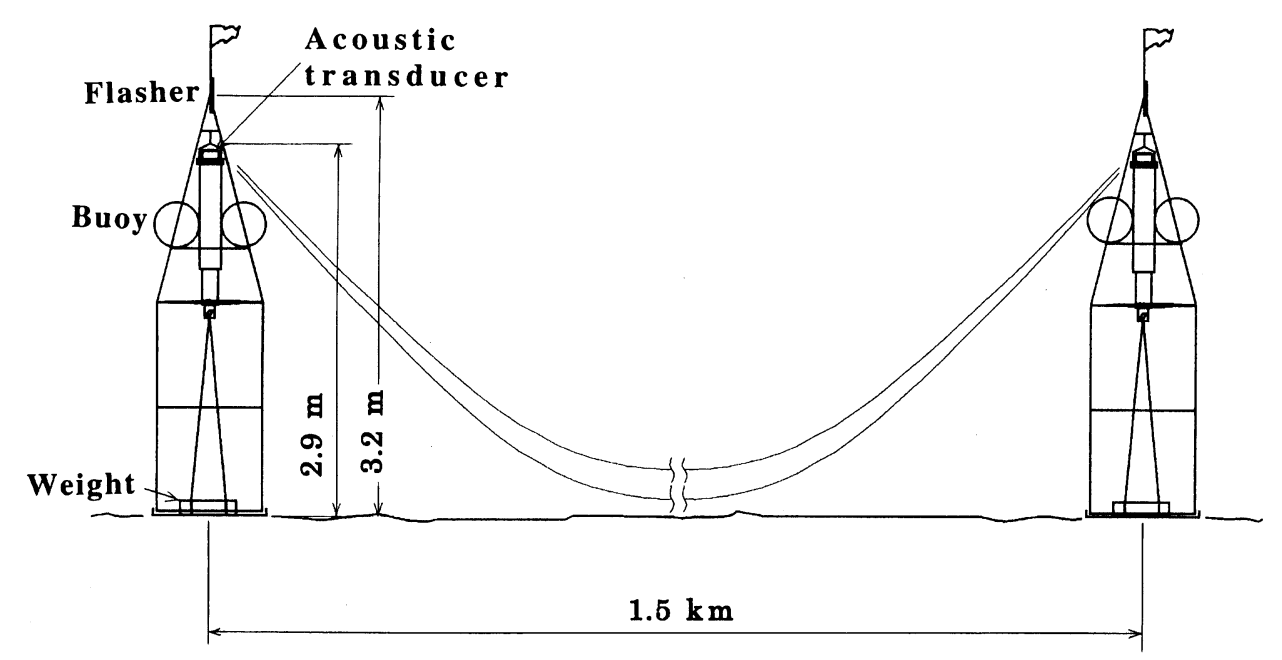

Fig. 1. Schematic illustration of seafloor acoustic ranging at a baseline length of about $1.5 \mathrm{~km}$ on the seafloor of Sagami Bay.

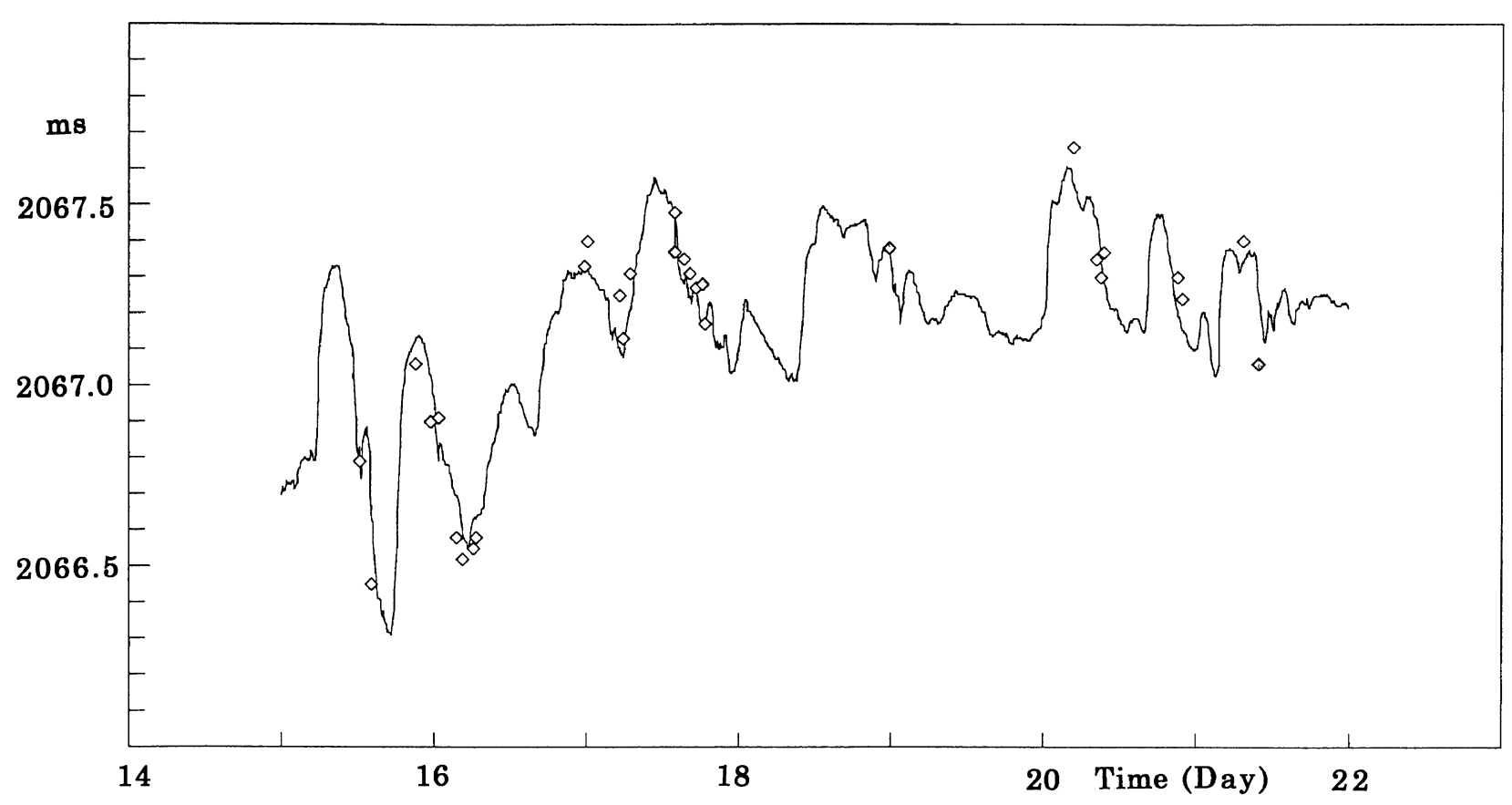

Fig. 2. Comparison between the observed values of two-way travel time of the acoustic signal (diamonds) and those estimated from the temperature observed at the ends of the baseline.

the same value as ambiguity in the acoustic ranging, we developed a ranging system using a 7-stage m-sequence acoustic signal. Theoretically speaking, the signal-to-noise ratio has increased by a factor 4. We deployed in March 1997 two units (A and B) on the seafloor of Sagami Bay with a distance of $1.35 \mathrm{~km}$. Measurements were carried out three times every 20 minutes, and we disregarded one result which showed the largest deviation among the three. Figure 3 shows a histogram of the difference between the selected two measurements. The results show that the above-mentioned problem of ambiguity has been improved but still reamins to be solved. If we solve this problem by repeated measurements, the repeatability of the acoustic ranging is better than $1 \mathrm{~cm}$.

\subsection{Detection of vertical movement}

We deployed three OBPs on the seafloor of Sagami Bay for about one day in February 1997. Figure 4(a) shows relative variation of pressure at two points about $180 \mathrm{~m}$ apart from each other. Water depth was about $1400 \mathrm{~m}$. The result shows a resolution of differential pressure measurement comparable to seafloor vertical displacement by $1 \mathrm{~cm}$. The differences result mainly from insufficient temperature corrections as shown in Fig. 4(b). The relative variation with the third one deployed about $5 \mathrm{~km}$ apart is about three times larger due to considerably different temperature variations. 

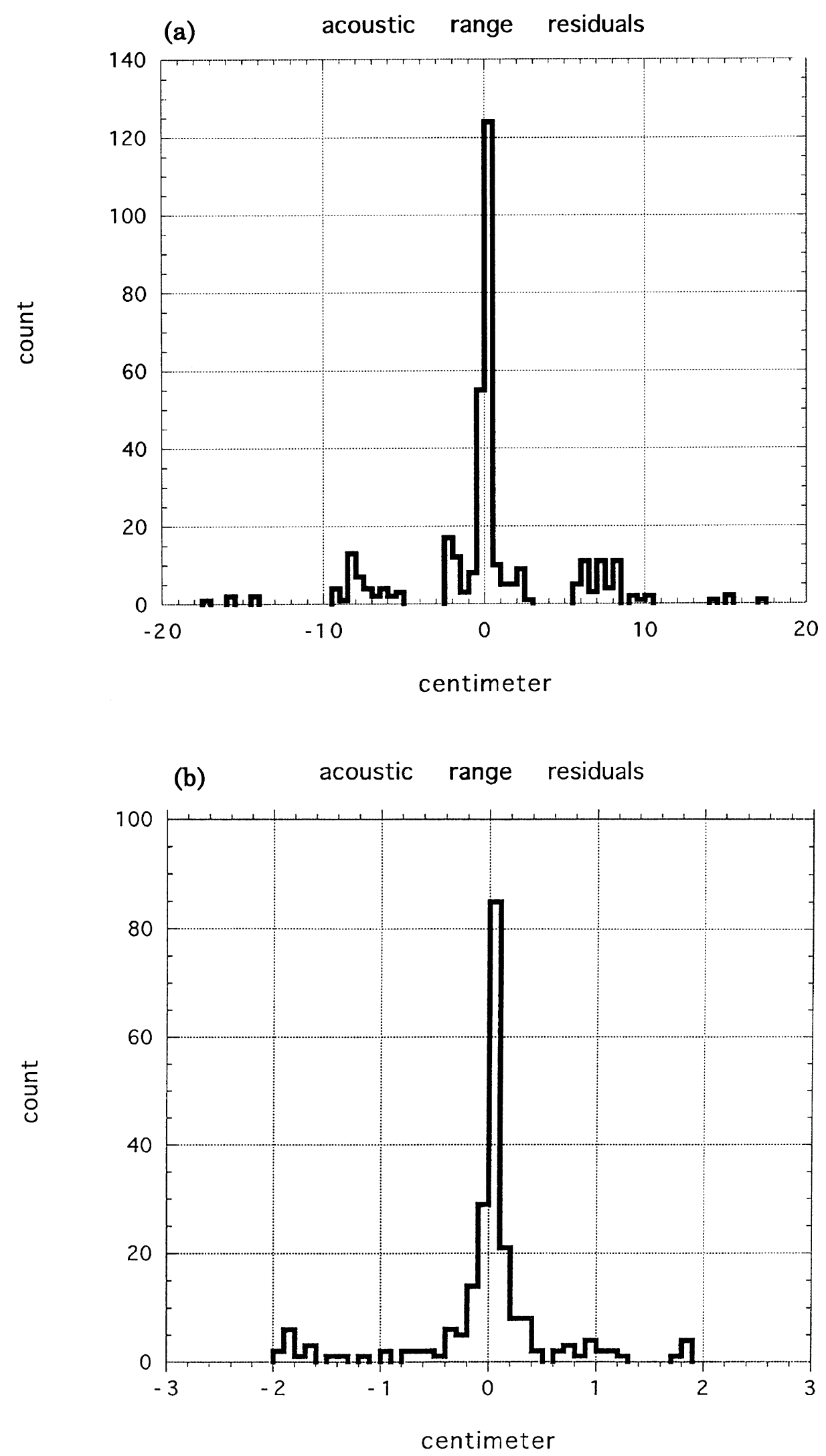

Fig. 3. Histogram of difference among the three successive measurements within 30 seconds at a baseline length of $1.35 \mathrm{~km}$ : (a) in the range -20 to $+20 \mathrm{~cm}$ and (b) in the range -2 to $+2 \mathrm{~cm}$. Results in (a) show ambiguities of $0.1 \mathrm{~ms}$, or about $7.5 \mathrm{~cm}$ in distance (see the text). The results show that repeatability of the acoustic ranging is better than $1 \mathrm{~cm}$ except for the ambiguity. 

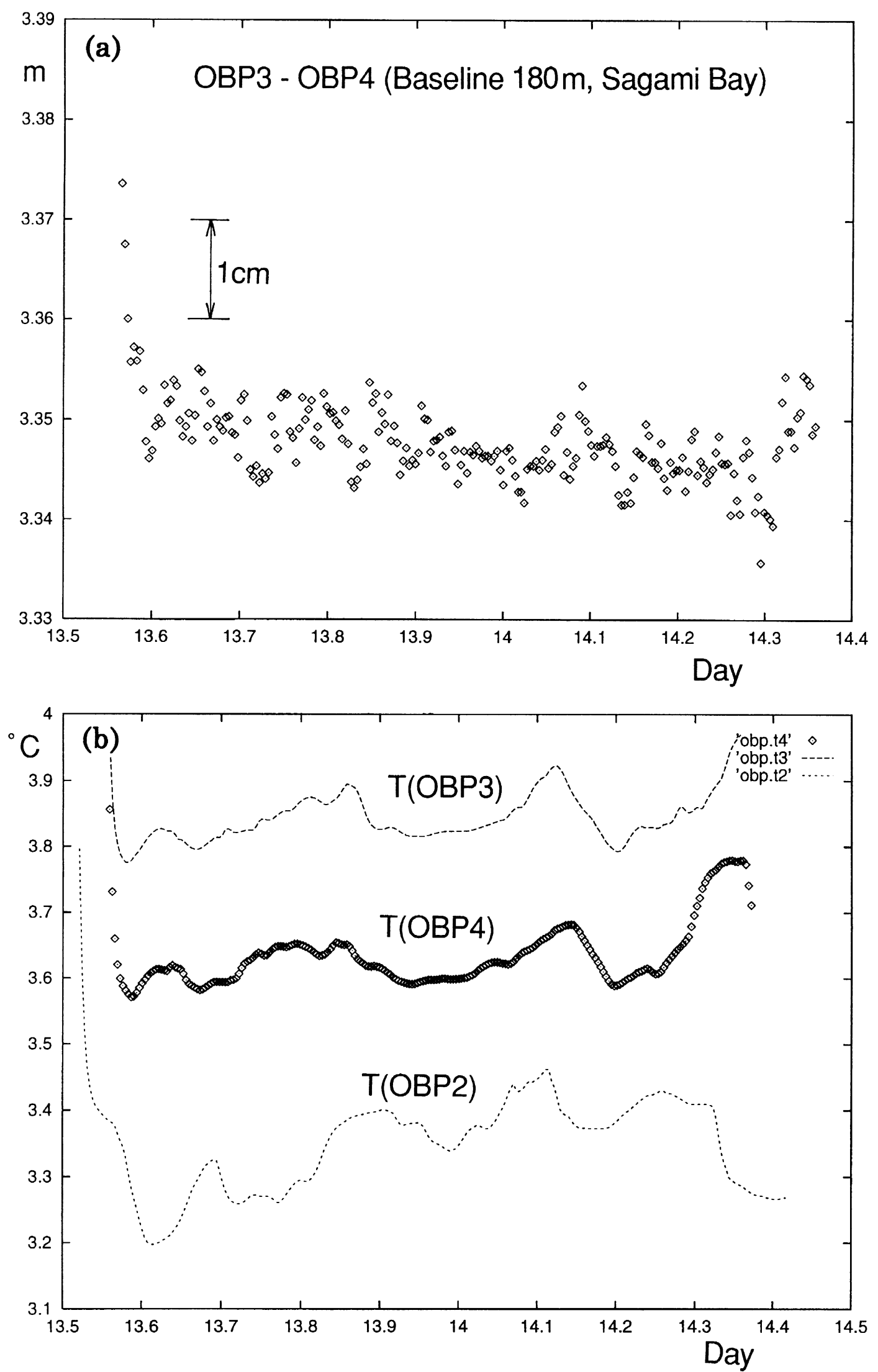

Fig. 4. (a) A result of differential pressure measurement at distance about $180 \mathrm{~m}$ on the seafloor of Sagami Bay (water depth about $1400 \mathrm{~m}$ ). (b) Temperature variations observed by the three OBPs for differential pressure measurement. 


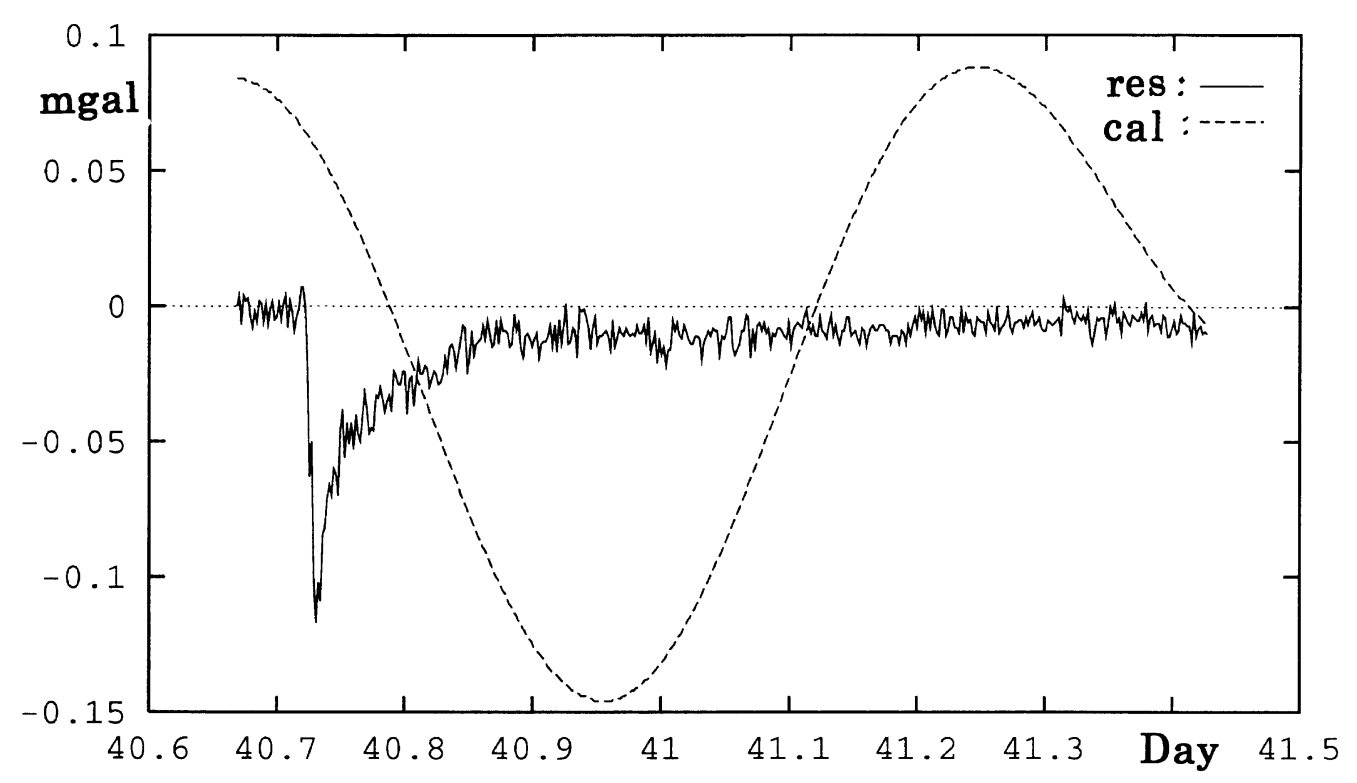

Fig. 5. A result of seafloor gravimetry for about one day on the shallow seafloor of Suruga Bay, Central Japan. The broken line shows theoretical values of tidal gravity variations ( $\mathrm{g}$-factor $=1.2$ ), and the small diamonds show observed values after the reduction of the effects of the earth tides, drift of the gravimeter $(0.34 \mathrm{mgal} / \mathrm{day})$, and one-dimensional effect of pressure variation. The big jump observed a few hours after the deployment is not an artifact; the data of water pressure and attitude of the gravimeter also show similar changes.

We carried out trial seafloor gravity measurements twice. We transported the OBG by car and on a small boat to a floating dock for the first trial in October 1996. We deployed the OBG with a rope and installed it on the seafloor at $32 \mathrm{~m}$ depth. The seafloor was much more stable than our laboratory in Tokyo and the gravity values observed over about three hours agreed well with theoretical gravity change due to the earth tides (Fujimoto et al., 1998). The r.m.s. residual was about 3 microgals. We pulled the OBG up several meters and reinstalled it on the seafloor. No effect of the redeployment was recognized. The effect of transportation by car and ship was also examined through comparison with the gravity values observed by a LaCoste \& Romberg land gravimeter Model G (G-124). The results show that the OBG has a repeatability of a few tens of microgals after transportation (Fujimoto et al., 1998).

The second sea trial was carried out in February 1998 on the seafloor of Suruga Bay, Central Japan. The gravimeter started from Tokyo (Ocean Research Institute, University of Tokyo), was used to measure gravity for one day on the seafloor at a water depth of about $90 \mathrm{~m}$, and then returned to Tokyo. The results of seafloor gravimetry are shown in Fig. 5. The broken line shows theoretical values of tidal gravity variations ( $\mathrm{g}$-factor $=1.2$ ), and the real line shows the residuals of the observed gravity values after the reduction of the effects of the earth tides, drift of the gravimeter $(0.34 \mathrm{mgal} / \mathrm{day})$, and one-dimensional effect of pressure variation. Considering the observed data of pressure and the attitude of the OBG, the large event a few hours after the deployment may be caused by a vertical movement of the instrument by about $35 \mathrm{~cm}$, but the cause of the motion has not been determined. There were no large earthquakes nearby during the time. The results after the event show that the OBG has a resolution of about 10 microgals on the seafloor, which corresponds to a vertical crustal movement of about $5 \mathrm{~cm}$. The drift of the gravimeter was checked at the starting point in Tokyo and at the pier of Mito-hama near the observation site at sea. The results were within a few tens of microgals after a drift correction with a constant value for the drift $(0.34 \mathrm{mgal} /$ day $)$. Several other tests we carried out on land show repeatability of gravity measurements by the gravimeter system comparable to a LaCoste \& Romberg land gravimeter.

\section{Discussion and Conclusions}

A seafloor experiment with acoustic ranging has shown a resolution better than $1 \mathrm{~cm}$ over a baseline length of $1 \mathrm{~km}$. The system is designed for ranging up to $7.5 \mathrm{~km}$, and we need further experiments at longer baselines at carefully selected experiment sites. Experiments are often carried out in Sagami Bay, where the sea condition is usually stable, but many ocean cables run in the valleys. Our experiment with an acoustic system with a 5 -stage $m$-sequence signal has shown that the effect of water temperature on the acoustic ranging could be corrected with r.m.s. residuals of $7 \mathrm{~cm}$. The residuals were caused partly by the ambiguity of $7.5 \mathrm{~cm}$ in acoustic ranging and partly by short-term fluctuations of temperature. The temperature was monitored only at the ends of the baseline. The short-term fluctuations may be better corrected with temperature monitoring in the middle of the baseline. If temperature on the deep seafloor is more stable by one order of magnitive, measurements of $1 \mathrm{~cm}$ at a baseline length of several kilometers can be a reasonable target.

In the case of precise positioning of the seafloor with the aid of kinematic GPS observation on the sea surface (Spiess et al., 1994; Chadwell et al., 1997), the situation is different. The temperature effect may be almost canceled out, if the 
temperature structure has a stable horizontal layering. But the upper several hundreds of meters of the ocean has strong currents, and the temperature varies by many degrees. We need further careful experiment to examine this problem.

A seafloor experiment with two pressure gauges about $180 \mathrm{~m}$ apart shows a resolution of differential pressure measurements comparable to seafloor vertical movements of $1 \mathrm{~cm}$. Since the residuals are estimated to result mainly from insufficient temperature corrections, we have to revise the correction considering the time constants of the sensors for pressure and temperature. We have carried out pressure measurements for more than 6 months at two stations about $2 \mathrm{~km}$ apart on the seafloor of Sagami Bay. The data will give us more information on the effectiveness of differential pressure measurement and its long-term stability.

The gravimeter system also has a resolution of about $10 \mathrm{mi}-$ crogals, or several centimeters in vertical motion. Since redeployment of the OBG has no effect on the gravimetry, gravimetry at several bench marks on the seafloor during a single submersible dive will be carried out with similar repeatability. The track of a dive is usually less than $2 \mathrm{~km}$, so we will need a few dives for precise gravimetric connection along a line of several kilometers. Gravity values on the seafloor has to be determined on the basis of calibration of the gravimeter at gravity points on land before and after the seafloor measurements. We estimate that repeatability of seafloor gravimetry is 20-30 microgals from the observed results before and after the sea trials. We plan repeated measurements at seafloor gravity bench marks to evaluate the repeatability. Because the sensor is in a temperature-regulated housing at about $36^{\circ} \mathrm{C}$, and because we have just one $\mathrm{OBG}$, long-term seafloor gravity measurement is not feasible at the moment.

In summary, we have developed basic systems for triangulation and leveling on the seafloor. The resolution is a few centimeters over a baseline length of $1 \mathrm{~km}$ or so for the moment, and will be revised through experiments at longer baselines. Although the resolution of tilt measurements given by differential pressure measurements is much lower than that of borehole systems, our systems with long baselines have a merit that they can detect displacements at a fault zone on the seafloor. An important problem for the next step is deployment of bench marks for cm-scale geodesy on the seafloor.

Acknowledgments. We owe much to H. Murakami, Kaiyo Denshi Inc., T. Furuta and A. Oshida, Kawasaki Geological Corp., and S. Matsuda, Clover Tech Inc., for able assistance in the development and sea trials of the seafloor instruments. We thank A. Kaneko, ORI, Univ. of Tokyo, for manufacturing the gimbal suspensions of the OBG. Anonymous reviewers provided constructive reviews. The instruments have been developed or modified under a grant from the Ministry of Education, Science, Sports and Culture: the Ocean Hemisphere Network Project.

\section{References}

Chadwell, C. D., F. N. Spiess, J. A. Hildebrand, L. E. Young, G. H. Purcell, Jr., and H. Dragert, Seafloor strain measurement using GPS and acoustics, in Gravity, Geoid and Marine Geodesy, IAG Symposia, vol. 117, edited by J. Segawa et al., pp. 682-689, Springer-Verlag Berlin Heidelberg, 1997. Dicke, R. H., Object detection system, U.S. Patent, no. 2,624,876, issued Jan. 6, 1953.

Fujimoto, H., T. Kanazawa, and H. Murakami, Seafloor acoustic ranging and the effect of temperature variation, in Gravity, Geoid and Marine Geodesy, IAG Symposia, vol. 117, edited by J. Segawa et al., pp. 690695, Springer-Verlag Berlin Heidelberg, 1997.

Fujimoto, H., A. Oshida, T. Furuta, and T. Kanazawa, Development of an ocean bottom gravimeter, J. Japan Soc. Mar. Sur. Tech., 10, 25-38, 1998 (in Japanese with English abstract).

Heki, K., G. R. Foulger, B. R. Julian, and C.-H. Jahn, Plate dynamics near divergent plate boundaries: geophysical implications of postrifting crustal deformation in NE Iceland, J. Geophys. Res., 98, 14279-14297, 1993.

Mackenzie, K. V., Nine-term equation for sound speed in the oceans, $J$. Acoust. Soc. Am., 79, 807-812, 1981.

MacWilliams, F. J. and N. J. A. Sloane, Pseudo-random sequences and arrays, Proc. IEEE, 64, 1715-1729, 1976.

Spiess, F. N., G. H. Purcell, and H. Dragert, Determination of sea floor displacements using precision transponders and GPS, in Proc. INSMAP 94, pp. 51-60, Mar. Tech. Soc., Washington, D.C., U.S.A., 1994.

Yabuki, T., Y. Nagaya, A. Asada, F. Ono, and K. Tajiri, Development of a seabottom horizontal distance meter for observation of seafloor movements, in Proc. INSMAP 94, pp. 493-498, Mar. Tech. Soc., Washington D.C., U.S.A., 1994.

H. Fujimoto (e-mail: fujimoto@ori.u-tokyo.ac.jp), K. Koizumi, Y. Osada, and T. Kanazawa 